\title{
The Structures of $\mathrm{S}_{4} \mathrm{~N} \ominus, \mathrm{S}_{3} \mathrm{~N}_{2} \mathrm{O}_{2}$ and $\mathrm{S}_{4} \mathrm{~N}_{3} \ominus$
}

\author{
Rolf Gleiter* and Richard Bartetzko \\ Institut für Organische Chemie der Universität, Im Neuenheimer Feld 270, D-6900 Heidelberg \\ Dedicated to Professor Josef Goubeau on the occasion of his 80th birthday
}

Z. Naturforsch. 36 b, 492-497 (1981); received December 22, 1980

Structural Isomers, MNDO Calculations, Transannular Interactions

Part of the potential surface of $\mathrm{S}_{4} \mathrm{~N}^{\ominus}$ has been investigated using the MNDO method. It is found that the cis-trans isomer $1 \mathrm{~b}$ is more stable by $20-30 \mathrm{~kJ} / \mathrm{mol}$ than the trans-trans isomer (1 c) and the cis-cis isomer (1 a). The stability of $\mathbf{1 b}$ is traced back to stabilization of the HOMO and to a Coulomb attraction. For $\mathrm{S}_{3} \mathrm{~N}_{2} \mathrm{O}_{2}(2)$ the MNDO calculations favour those isomers ( $\mathbf{2} \mathbf{a}$ and $\mathbf{2 b}$ ) with two sickle-like arrangements for the same reasons. For $\mathrm{S}_{4} \mathrm{~N}_{3}{ }^{\ominus}(\mathbf{3})$ only one isomer (3a) is favoured due to the stabilization of the HOMO. The similarity in the transannular interaction present in 1-3 and that in trithiapentalenes and related compounds is pointed out. The PE spectrum of 2 has been reinvestigated. The first five bands can be interpreted by comparison between the measured ionization potentials and the calculated (MNDO) orbital energies.

Recently the structures of three sulfur nitrogen compounds have been reported containing at least one sickle-like arrangement: $\mathrm{S}_{4} \mathrm{~N}^{\ominus}(\mathbf{1})[1], \mathrm{S}_{3} \mathrm{~N}_{2} \mathrm{O}_{2}(2)$ [2] and $\mathrm{S}_{4} \mathrm{~N}_{3} \ominus(3)$ complexed to Pt [3]. Structural data for all three compounds are displayed in Fig. 1. Common to all three structures are transannular $\mathrm{S} \cdots \mathrm{S}, \mathrm{S} \cdots \mathrm{O}$ and $\mathrm{S} \cdots \mathrm{N}$ distances below the sum of the corresponding van der Waals radii.
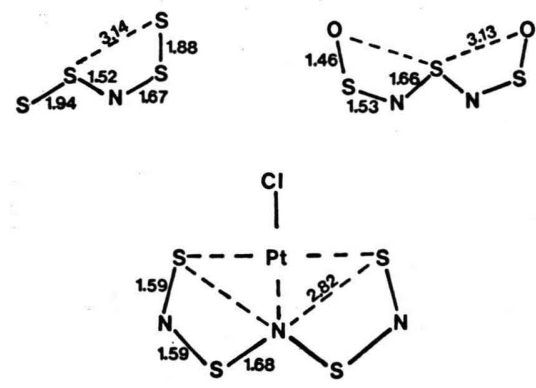

Fig. 1. Bond lengths of $\mathrm{S}_{4} \mathrm{~N} \ominus, \mathrm{S}_{3} \mathrm{~N}_{2} \mathrm{O}_{2}$ and $\mathrm{S}_{4} \mathrm{~N}_{3} \mathrm{PtCl}$.

To explain the structure of $\mathrm{S}_{4} \mathrm{~N}^{\ominus} a b$ initio calculations using Slater type basis functions have been carried out [1]. These investigations indicate an $8 \pi$ system with relatively strong negative charges $(-.42,-.44)$ at the terminal sulfur centers and the nitrogen $(-0.35)$. The configuration found for $\mathbf{1}$ is tentatively ascribed as due to an electrostatic interaction between terminal and internal sulfur atoms. For the latter positive charges $(0.01$ and 0.20$)$ are predicted.

* Reprint requests to Prof. Dr. R. Gleiter. 0340-5087/81/0400-0492/\$01.00/0
In connection with our interest in possible isomerizations latent in compounds containing sulfur and nitrogen [4] the most likely configurations of 1-3 were of interest.

Specific questions are:

1. What is the energy difference between different isomers?

2. Why are the configurations found in Nature preferred? and in case of $\mathbf{l}$ (where the relatively small number of atoms allows the calculation of a surface):

3. What are the transition states between the different configurations?

To answer these questions we have carried out molecular orbital (MO) calculations using the MNDO model [5].

\section{Calculations on $\mathrm{S}_{4} \mathrm{~N}^{\ominus}(\mathbf{1})$}

In case of $\mathrm{S}_{4} \mathrm{~N}^{\ominus}$ we have investigated the potential energy as a function of the angles $\alpha$ and $\beta$ (in plane movement) by varying them from 105 to $270^{\circ}$ independently, starting from the cis-cis conformation (1a) shown below. A second potential surface has been derived by changing the angles $\gamma$ and $\delta$ (out of plane movement) independently. One parameter $(\gamma)$ was varied from $0^{\circ}$ to $360^{\circ}$, the other one $(\delta)$ from 0 to $180^{\circ}$. All other geometrical parameters were optimized with respect to the energy. The potential surfaces obtained for the two pairs of variables ( $\alpha, \beta$ on one side and $\gamma, \delta$ on the other) look very similar in so far as both exhibit equivalent 


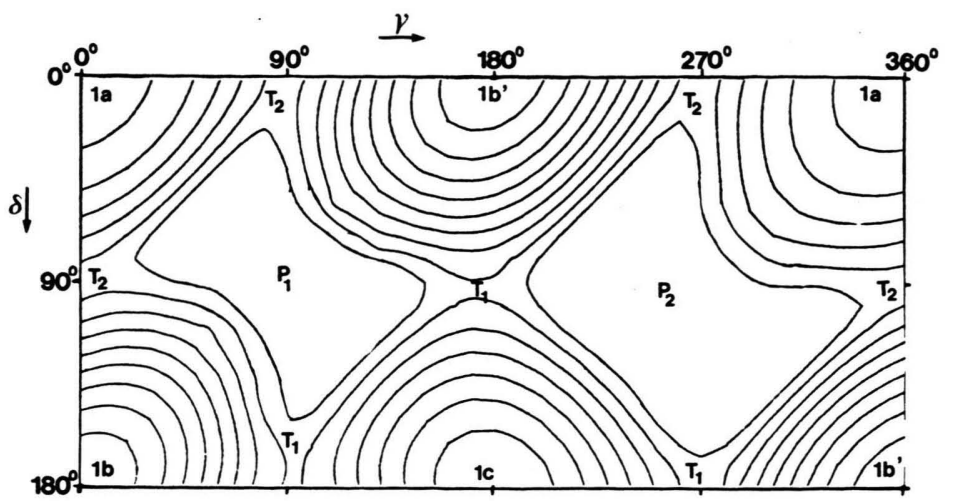

Fig. 2. Total energy of $\mathrm{S}_{4} \mathrm{~N}^{\ominus}$ as a function of $\gamma$ and $\delta$. The contours are drawn for every $0.1 \mathrm{eV}$. For the meaning of $\mathrm{T}_{1}, \mathrm{~T}_{2}, \mathrm{P}_{1}$ and $\mathrm{P}_{2}$ see text. Around $\mathrm{P}_{1}$ and $\mathrm{P}_{2}$ self consistency could not always be achieved therefore the energy contours could not be drawn.<smiles>SS[As]1N[As]SS1</smiles>

1a $\left(\alpha=\beta=120^{\circ}\right)$<smiles>SSNSS</smiles><smiles>SSNSS</smiles>

1b' $1 c$

minima for the cis-trans isomers $\mathbf{1 b}$ and $\mathbf{1} \mathbf{b}^{\prime}$ and local minima for the cis-cis isomer (1a) and the trans-trans isomer (1c). As an example we show the energy map resulting from the out-of-plane movement of the terminal $\mathrm{S}$ atoms in Fig. 2. It turned out that the in plane movement of the terminal $\mathrm{S}$ atoms affords more energy than the changes of $\gamma$ and $\delta$. The potential surface in Fig. 2 shows three minima for $\delta=180^{\circ}, \gamma=0^{\circ}(\mathbf{l b}), \delta=0^{\circ}, \gamma=180^{\circ}$ $\left(1 \mathbf{b}^{\prime}\right)$ and $\gamma=360^{\circ}, \delta=180^{\circ}\left(1 \mathbf{b}^{\prime}\right)$. Local minima are encountered for $\gamma=0^{\circ}, \delta=0^{\circ}$ (1 a), $\gamma=360^{\circ}, \delta=0^{\circ}$ (1 a) and $\delta=180^{\circ}, \gamma=180^{\circ}$ (1 c). The heat of formations of $1 \mathbf{a}, \mathbf{1 b}$ and $\mathbf{1} \mathbf{c}$ are given in Tab. I. Further distinguished points of the potential surface are two peaks, $P_{1}$ and $P_{2}$, for turning $\mathrm{S}^{4}$ and $\mathrm{S}^{5}$ out of the molecular plane defined by $\mathrm{S}^{2} \mathrm{~N}^{1} \mathrm{~S}^{3}$. One peak, $P_{1}$, corresponds to the conformation where $\mathrm{S}^{4}$ and $\mathrm{S}^{5}$ are syn to each other the other one, $P_{2}$, where $\mathrm{S}^{4}$ and $S^{5}$ are anti to each other. The path of minimum energy from $1 \mathbf{b}\left(\delta=180^{\circ}, \gamma=0^{\circ}\right)$ to $1 \mathbf{b}^{\prime}(\delta=0$ or $360^{\circ}, \gamma=180^{\circ}$ ) via the trans-trans isomer $1 \mathrm{c}$ is predicted to be only slightly lower than via 1 a. The geometry of the corresponding transition states $\left(T_{1}, T_{2}\right)$ (all remaining geometrical parameters optimized is given in Table I).

In Fig. 3 the energy profiles along the two different paths, $1 \mathrm{~b}-T_{1}-1 \mathrm{c}$ and $\mathbf{1 b}-T_{2}-\mathbf{1}$ a are depicted.

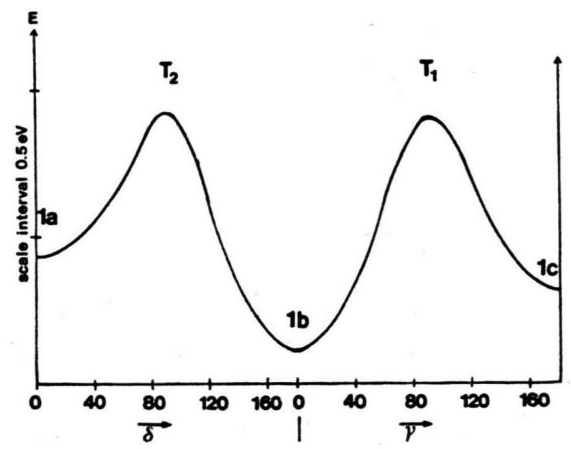

Fig. 3. Energy profiles along the paths $1 \mathrm{~b}-\mathrm{T}_{1}-1 \mathrm{c}$ and $1 \mathbf{b}-\mathbf{T}_{2}-1$ a of Fig. 2.

Table I. Calculated geometrical parameters for different configurations of $\mathbf{1}$ according to the MNDO model.

\begin{tabular}{|c|c|c|c|c|c|c|c|c|c|c|}
\hline \multirow[b]{2}{*}{ Configuration } & \multicolumn{2}{|c|}{ Bond lengths $[\AA$} & \multirow{2}{*}{$\mathrm{S}^{2} \mathrm{~S}^{4}$} & \multirow[b]{2}{*}{$\mathrm{S}^{3} \mathrm{~S}^{5}$} & \multicolumn{2}{|c|}{ Bond angles $\left[{ }^{\circ}\right]$} & \multirow{2}{*}{\multicolumn{2}{|c|}{$\mathrm{N}^{1} \mathrm{~S}^{3} \mathrm{~S}^{5}$}} & & \multirow[b]{2}{*}{$\mathrm{H}_{\mathrm{f}}[\mathrm{kJ} / \mathrm{mol}]$} \\
\hline & $\mathbf{N}^{1} \mathbf{S}^{2}$ & $\mathrm{~N}^{1} \mathrm{~S}^{3}$ & & & $\mathbf{S}^{2} \mathbf{N}^{1} \mathbf{S}^{3}$ & $\mathrm{~N}^{1} \mathbf{S}^{2} \mathrm{~S}^{4}$ & & & & \\
\hline $1 \mathbf{a}$ & 1.546 & 1.546 & 1.852 & 1.852 & 144 & 120 & 120 & 0 & 0 & 73.66 \\
\hline $1 \mathrm{~b}$ & 1.562 & 1.558 & 1.863 & 1.864 & 127 & 106 & 113 & 180 & 0 & 42.30 \\
\hline $1 \mathrm{c}$ & 1.573 & 1.573 & 1.863 & 1.863 & 117 & 108 & 108 & 180 & 180 & 61.28 \\
\hline $\mathrm{T}_{1}$ & 1.536 & 1.644 & 1.846 & 1.880 & 116 & 109 & 105 & 90 & 180 & 119.66 \\
\hline $\mathrm{T}_{2}$ & 1.518 & 1.625 & 1.837 & 1.888 & 131 & 105 & 119 & 90 & 0 & 122.24 \\
\hline
\end{tabular}


Table II. Calculated Wiberg bond indices and net charges of $\mathbf{1}$ according to the MNDO model.

\begin{tabular}{|c|c|c|c|c|c|c|c|c|c|c|c|}
\hline Configuration & $\mathrm{N}^{1}-\mathrm{S}^{2}$ & $\mathrm{~N}^{1}-\mathrm{S}^{3}$ & $\mathrm{~S}^{2}-\mathrm{S}^{4}$ & $\mathrm{~S}^{3}-\mathrm{S}^{5}$ & $S^{4}-S^{5}$ & $\mathrm{~S}^{2}-\mathrm{S}^{5}$ & $\mathrm{~N}^{1}$ & $\mathrm{~S}^{2}$ & $\mathrm{~S}^{3}$ & $\mathrm{~S}^{4}$ & $\mathrm{~S}^{5}$ \\
\hline $1 \mathbf{a}$ & 1.28 & 1.28 & 1.06 & 1.06 & 0.024 & - & -.40 & .34 & .34 & -.64 & -.64 \\
\hline $1 \mathrm{~b}$ & 1.33 & 1.30 & 1.06 & 1.04 & - & 0.067 & -.34 & .36 & .31 & -.64 & -.68 \\
\hline 1c & 1.31 & 1.31 & 1.04 & 1.04 & - & - & -.28 & .25 & .25 & -.61 & -.61 \\
\hline
\end{tabular}

The energy difference between the minima is relatively small $(20-30 \mathrm{~kJ} / \mathrm{mol})$. It is interesting to notice that the sickle-like structure, $\mathbf{l b}$, is favoured by about $20-30 \mathrm{~kJ} / \mathrm{mol}$ as compared with other isomers. A second result worth to keep in mind is the relatively low energy barrier $(50-80 \mathrm{~kJ} / \mathrm{mol})$ between the different valleys. The prediction that the change of $\gamma$ and $\delta$ (out of plane movement) is more economical for $\mathrm{S}_{4} \mathrm{~N}^{\ominus}$ than the change of $\alpha$ and $\beta$ (in plane movement) in any case can be traced back to the fact that we are dealing with an $8 \pi$ system, i.e. four of the five $\pi$-niveaus are occupied and thus the $\pi$-bond order is reduced because one $\pi^{*}$ orbital is occupied as well. The highest occupied and lowest unoccupied molecular orbitals (HOMO and LUMO) of $\mathbf{1}$ in $\mathbf{1 b}$ are shown schematically below. From this

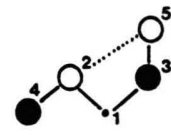

HOMO

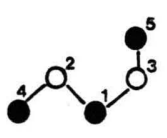

LUMO drawing it is evident that in case of the cis-trans isomer (1) the spatial interaction between $\mathrm{S}^{2}$ and $\mathrm{S}^{5}$ contributes to the lowering of its energy. This analysis is in line with a treatment dealing with the stability of isomers of extended $\pi$ systems given by Hoffmann and Olofson [6]. The overlap populations and atomic charges predicted according to the MNDO model are given in Table II. Both results parallel those obtained by ab initio methods [1].

\section{Calculations on $\mathrm{S}_{3} \mathrm{~N}_{2} \mathrm{O}_{2}(2)$ and $\mathrm{S}_{4} \mathrm{~N}_{3}{ }^{\ominus}$ (3)}

Due to the larger number of atoms of $\mathrm{S}_{3} \mathrm{~N}_{2} \mathrm{O}_{2}(2)$ compared with $\mathrm{S}^{4} \mathrm{~N}^{\ominus}$ more configurations are possible in a chain-arrangement. The most likely ones

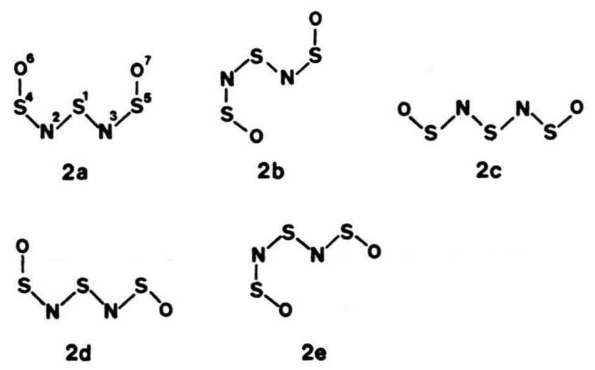

are 2a-2e for which a planar arrangement with a bent NSO group is pertained. Using again the MNDO method [5] we have calculated their structures by minimizing the energy with respect to all geometrical parameters. The resulting structural parameters as well as the heat of formation $\left(\mathrm{H}_{1}\right)$ are given in Table III. According to these results those structures with two sickle-like arrangements (2a and $\mathbf{2 b}$ ) are more stable than the structures with

Table III. Calculated geometrical parameters and heat of formation $\left(\mathbf{H}_{\mathrm{f}}\right)$ for different configurations of 2 according to the MNDO method.

\begin{tabular}{|c|c|c|c|c|c|c|}
\hline $\begin{array}{l}\text { Con- } \\
\text { figu- } \\
\text { ra- } \\
\text { tion } \\
\end{array}$ & $\begin{array}{l}\text { Bond lengths }[\AA] \\
\mathrm{S}^{1}-\mathrm{N}^{2} \mathrm{~N}^{2}-\mathrm{S}^{4} \mathrm{~S}^{4}-\mathrm{O}^{6} \mathrm{~S}^{1}-\mathrm{N}^{3} \mathrm{~N}^{3}-\mathrm{S}^{5} \mathrm{~S}^{5}-\mathrm{O}^{7}\end{array}$ & $\begin{array}{l}\text { Bond angle }\left[{ }^{\circ}\right] \\
\mathrm{N}^{2}-\mathrm{S}^{1}-\mathrm{N}^{3} \mathrm{~S}^{1}-\mathrm{N}^{2}-\mathrm{S}^{4}\end{array}$ & $\mathrm{~N}^{2}-\mathrm{S}^{4}-\mathrm{O}^{6}$ & $\mathrm{~S}^{1}-\mathrm{N}^{3}-\mathrm{S}^{5}$ & $\mathrm{~N}^{3}-\mathrm{S}^{5}-\mathrm{O}^{7}$ & $\begin{array}{l}\mathrm{H}_{f} \\
{[\mathrm{~kJ} / \mathrm{mol}]}\end{array}$ \\
\hline $\mathbf{2 a}$ & $\begin{array}{llllll}1.610 & 1.526 & 1.482 & 1.610 & 1.526 & 1.482\end{array}$ & 129 & 111 & 129 & 111 & 523.91 \\
\hline $2 \mathbf{b}$ & $\begin{array}{llllll}1.584 & 1.522 & 1.478 & 1.602 & 1.523 & 1.481\end{array}$ & 142 & 113 & 132 & 110 & 518.60 \\
\hline $2 \mathrm{e}$ & $\begin{array}{llllll}1.623 & 1.550 & 1.482 & 1.623 & 1.550 & 1.482\end{array}$ & 117 & 104 & 117 & 104 & 577.88 \\
\hline 2d & $\begin{array}{llllll}1.611 & 1.528 & 1.482 & 1.621 & 1.547 & 1.482\end{array}$ & 128 & 111 & 119 & 104 & 549.98 \\
\hline $2 \mathbf{e}$ & $\begin{array}{llllll}1.585 & 1.523 & 1.475 & 1.612 & 1.543 & 1.481\end{array}$ & 141 & 114 & 121 & 105 & 549.61 \\
\hline
\end{tabular}


Table IV. Calculated Wiberg bond indices and net charges of 2 according to the MNDO method. For the numbering of the atoms see text.

\begin{tabular}{|c|c|c|c|c|c|c|c|c|c|c|c|c|c|c|c|}
\hline \multirow{2}{*}{$\begin{array}{l}\text { Confi- } \\
\text { guration }\end{array}$} & \multirow{2}{*}{\multicolumn{3}{|c|}{$\begin{array}{l}\text { Wiberg bond indices } \\
\mathrm{S}^{1}-\mathrm{N}^{2} \mathrm{~S}^{1}-\mathrm{N}^{3} \mathrm{~N}^{2}-\mathrm{S}^{4}\end{array}$}} & \multirow[b]{2}{*}{$\mathrm{N}^{3}-\mathrm{S}^{5}$} & \multirow[b]{2}{*}{$\mathrm{S}^{4}-\mathrm{O}^{6}$} & \multirow[b]{2}{*}{$\mathrm{S}^{5}-\mathrm{O}^{7}$} & \multirow[b]{2}{*}{$\mathrm{S}^{1}-\mathrm{O}^{6}$} & \multirow[b]{2}{*}{$\mathrm{S}^{1}-\mathrm{O}^{7}$} & \multicolumn{3}{|c|}{ Net charges } & \multirow[b]{2}{*}{$\mathbf{S}^{4}$} & \multirow[b]{2}{*}{$\mathbf{S}^{5}$} & \multirow[b]{2}{*}{$\mathrm{O}^{6}$} & \multirow[b]{2}{*}{$\mathrm{O}^{7}$} \\
\hline & & & & & & & & & $\mathbf{S}^{1}$ & $\mathrm{~N}^{2}$ & $\mathrm{~N}^{3}$ & & & & \\
\hline $2 \mathbf{a}$ & 1.039 & 1.039 & 1.488 & 1.488 & 1.338 & 1.378 & 0.053 & 0.053 & .40 & -.50 & -.50 & .87 & .87 & -.57 & -.57 \\
\hline $2 \mathrm{~b}$ & 1.068 & 1.017 & 1.447 & 1.472 & 1.355 & 1.338 & 0.056 & 0.053 & .47 & -.55 & -.57 & .89 & .90 & -.56 & -.58 \\
\hline $2 \mathrm{c}$ & 1.038 & 1.038 & 1.471 & 1.471 & 1.382 & 1.382 & 0.049 & 0.049 & .22 & -.42 & -.42 & .78 & .78 & -.47 & -.47 \\
\hline $2 d$ & 1.042 & 1.037 & 1.496 & 1.468 & 1.335 & 1.381 & 0.053 & 0.049 & .32 & -.47 & -.45 & .87 & .80 & -.57 & -.48 \\
\hline $\mathbf{2 e}$ & 1.065 & 1.018 & 1.440 & 1.446 & 1.376 & 1.382 & 0.058 & 0.051 & .39 & -.54 & -.53 & .89 & .81 & -.53 & -.48 \\
\hline
\end{tabular}

one sickle-like arrangement (2d and $\mathbf{2 e})$. The structure $2 \mathrm{c}$ with the all trans arrangement is even less stable than $2 d$ and $2 \mathbf{e}$. The energy difference between $2 \mathrm{c}$ and $2 \mathrm{~d}$ and $2 \mathrm{e}$ is $28 \mathrm{~kJ} / \mathrm{mol}$. The difference between the latter and $\mathbf{2} \mathbf{a}$ and $\mathbf{2 b}$ amounts to 26 and $31 \mathrm{~kJ} / \mathrm{mol}$ respectively. Both differences suggest that the gain due to transannular interactions for one sickle-part is in the order of $26-30 \mathrm{~kJ} / \mathrm{mol}$. A similar energy difference is predicted between the

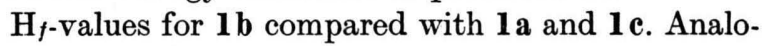
gous to $\mathbf{1}$ stabilization of $\mathbf{2 a}$ and $\mathbf{2 b}$ can be traced back to a Coulomb interaction between the negatively charged oxygen centers and the positively charged sulfur atoms and to an in-phase relation of the HOMO in a sickle arrangement. The HOMO and

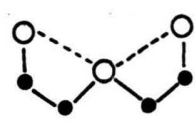

номо

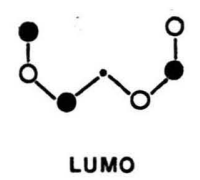

LUMO of $\mathbf{2}$ in $\mathbf{2 a}$ as derived by an MNDO calculation is scetched below. It is seen that in this sicklelike arrangement the coefficient of the $\mathrm{O}$ atomic orbital $\left(\mathrm{p}_{\mathbf{z}} \mathrm{AO}\right)$ in the HOMO has the same sign as the $\mathrm{AO}$ coefficient at the sulfur atoms. This in-phase relation leads to a weakly bonding interaction as can be seen from the Wiberg bond indices [7] given in Table IV. Parallel to this interaction there is a strong Coulomb attraction between the central $\mathrm{S}$ atom and the oxygen atoms as seen from the calculated net charges (Table IV).

Related to the structure of $\mathbf{2}$ is $\mathrm{S}_{4} \mathrm{~N}_{3}{ }^{\ominus}(3)$ in so far as five of the seven $\pi$-orbitals are occupied. It has been isolated recently as a ligand in the $\mathrm{S}_{4} \mathrm{~N}_{3} \mathrm{PtCl}$ complex [3]. As in the case of 2 five configurations $(\mathbf{3 a}-\mathbf{3 e})$ seem most likely. The heats of formation

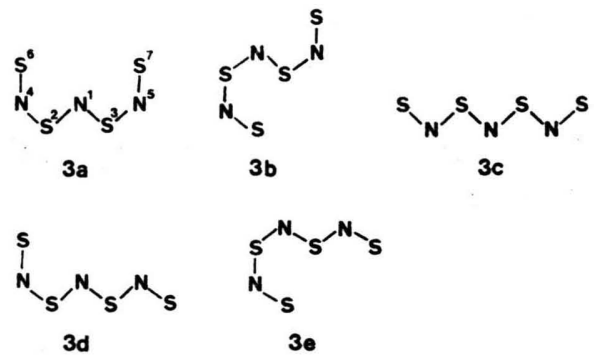

calculated for 3a-3e are listed in Table $\mathrm{V}$ together with the bond lengths and angles. It is seen that configuration $\mathbf{3 a}$ is predicted to be the most stable one, but the difference in the heat of formation to $\mathbf{3 d}, \mathbf{3 b}$ and $3 \mathrm{c}$ is relatively small and within the

Table V. Calculated geometrical parameters, heat of formation $\left(\mathrm{H}_{\mathrm{j}}\right)$ and net charges for different configuration of 3 according to MNDO. For the numbering see formulas in the text.

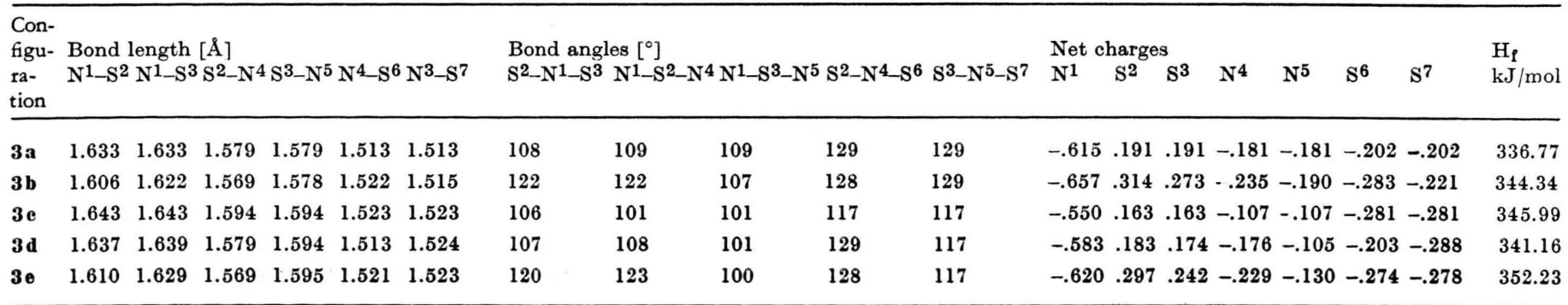


error limit of the method. It is interesting to notice that for 3 the calculation predicts partial negative charges for the terminal sulfur atoms $\left(\mathbf{S}^{6}\right.$ and $\left.\mathrm{S}^{7}\right)$ as well as for the central nitrogen atom $\left(\mathrm{N}^{1}\right)$ (see Table V). The Coulomb attraction argument for the preference of $\mathbf{3}$ a fails in this case. As anticipated the HOMO and LUMO for 3 show the same nodal properties as in case of 2 and thus because of the relative short $\mathrm{N}^{1} \mathrm{~S}^{6}$ and $\mathrm{N}^{1} \mathrm{~S}^{7}$ distance the stability of $\mathbf{3 a}$ can be understood in terms of transannular bonding interactions in the HOMO.

\section{PE Spectrum of 2}

A further check for the validity of the MNDO results is provided by comparison of the $\varepsilon_{j}$ values with the vertical ionization potentials, $I_{v, j}$, derived from the $\mathrm{He}(\mathrm{I})$ photoelectron (PE) spectrum of 2. Since our assignment differs from that reported in the literature (see Table VI) [8] with respect to the number of bands for the broad peak around $11.2 \mathrm{eV}$, we have remeasured the PE spectrum (see Fig. 4). We find three peaks below $13 \mathrm{eV}$; two of them (bands (1) and (5) are well separated from a third broad one consisting of three strongly overlapping bands (bands 2-4). A comparison with the orbital energies, $\varepsilon_{\mathfrak{j}}$, calculated by MNDO shows an excellent agreement if we assume the validity of Koopmans' theorem $\left(-\varepsilon_{\mathrm{j}}=\mathrm{I}_{\mathrm{v}, \mathrm{j}}\right)[9]$.
Table VI. Comparison between measured vertical ionization potentials, $I_{v, j^{\prime}}$ and calculated (MNDO) orbital energies, $\varepsilon_{j}$, of $2 \mathbf{a}\left(\mathrm{C}_{2 \mathrm{v}}\right)$ and $2 \mathrm{~b}\left(\mathrm{C}_{\mathrm{s}}\right)$. All values in $\mathrm{eV}$.

\begin{tabular}{lrll}
\hline Bands & \multicolumn{1}{l}{$\mathrm{I}_{\mathrm{v}, \mathrm{j}}$} & \multicolumn{1}{l}{$\varepsilon_{\mathrm{j}}(2 \mathrm{a})^{*}$} & $\varepsilon_{\mathrm{j}}(2 \mathrm{~b})^{*}$ \\
\hline 1 & 9.25 & $-9.55\left(3 \mathrm{~b}_{1}, \pi\right)$ & $-9.34\left(5 \mathrm{a}^{\prime \prime}, \pi\right)$ \\
2 & 11.08 & $-11.23\left(2 \mathrm{a}_{2}, \pi\right)$ & $-11.19\left(4 \mathrm{a}^{\prime \prime}, \pi\right)$ \\
3 & 11.38 & $-11.51\left(8 \mathrm{a}_{1}, n\right)$ & $-11.39\left(15 \mathrm{a}^{\prime}, n\right)$ \\
4 & 11.60 & $-11.64\left(7 \mathrm{~b}_{2}, n\right)$ & $-11.58\left(14 \mathrm{a}^{\prime}, n\right)$ \\
5 & 12.51 & $-12.35\left(7 \mathrm{a}_{1}, n\right)$ & $-12.68\left(13 \mathrm{a}^{\prime}, n\right)$
\end{tabular}

* The numbering refers to the valence orbitals only.

\section{Final Remarks}

The stability of those isomers with transannular interactions resulting in relatively short $\mathrm{S} \cdots \mathrm{S}(\mathbf{1} \mathbf{b})$ and $S \cdots O(2 a)$ distances below the sum of the van der Waals radii resembles very much the situation in trithiapentalenes and related species [10]. In these compounds the preponderance of the U shape has been ascribed to a "delicate balance between the repulsive interactions (repulsion of the nuclei and the lone pairs) and attractive forces ( $p \pi-p \pi$ interaction and $p_{\sigma}-3 \mathrm{~d}$ or $4 \mathrm{~s}$ interaction)" [10]. In this connection it is interesting to notice that we have not included $3 \mathrm{~d}$ or $4 \mathrm{~s}$ orbitals on the sulfur

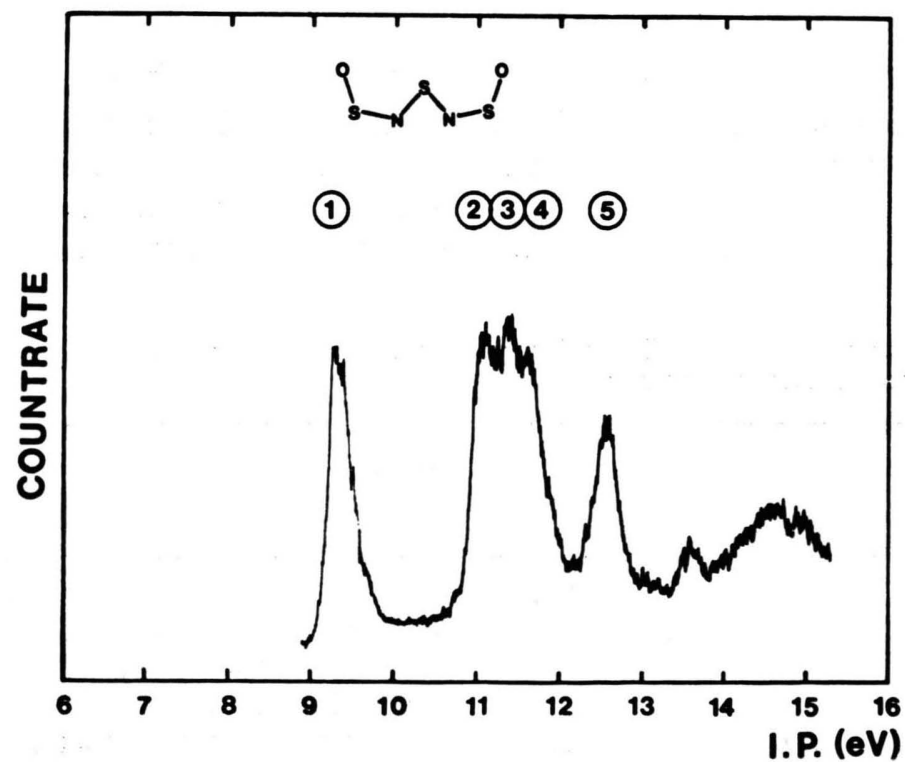

Fig. 4. $\mathrm{He}(\mathrm{I})$ photoelectron spectrum of 2. 
centers in our basis set and yet our model calculations reproduce experimental results for $\mathbf{1}$ and $\mathbf{2}$ remarkable well. This good agreement suggests that also our results concerning the stability of $\mathbf{2 b}$ are reliable and its existence should at least be detectable in the gas phase or in solution. The fact that $\mathbf{2 a}$ only has been isolated in the solid state might be due to packing effects. In view of the relatively small energy differences between $1 \mathbf{b}$ and $1 \mathbf{a}$ it might be worthwhile to offer $\mathrm{S}_{4} \mathrm{~N}^{\ominus}$ different cations.

We are grateful to the Fonds der Chemischen Industrie, the Deutsche Forschungsgemeinschaft and the BASF in Ludwigshafen for financial support.
[1] T. Chivers, W. G. Laidlaw, R. T. Oakley, and M. Trsic, J. Am. Chem. Soc. 102, 5773 (1980).

[2] J. Weiß, Z. Naturforsch. 16 b, 477 (1961); R. Steudel, J. Steidel, and N. Rautenberg, Z. Naturforsch. $35 \mathrm{~b}, 792$ (1980).

[3] H. Endres and E. Galantai, Angew. Chem. 92, 644 (1980); Angew. Chem. Int. Ed. Engl. 19, 653 (1980).

[4] R. Gleiter, J. Chem. Soc. A 1970, 3174; R. Bartetzko and R. Gleiter, Inorg. Chem. 17, 995 (1978); R. Bartetzko and R. Gleiter, Chem. Ber. 113, 1138 (1980); R. Gleiter, R. Bartetzko, and
P. Hofmann, Z. Naturforsch. 35b, 1166 (1980).

[5] M. J. S. Dewar and W. Thiel, J. Am. Chem. Soc. 99, 4899 (1977).

[6] R. Hoffmann and R. A. Olofson, J. Am. Chem. Soc. 88, 943 (1966).

[7] K. B. Wiberg, Tetrahedron 24, 1083 (1968).

[8] M. V. Andreocci, M. Bossa, V. Dilastro, C. Furlani, G. Mattogno, and H. W. Roesky, Z. Phys. Chem. N. F. 118, 137 (1979).

[9] T. Koopmans, Physica 1, 104 (1934).

[10] R. Gleiter and R. Gygax, Topics Curr. Chem. 63, 49 (1976). 